\title{
A Study of Salivary Glands of Rats Injected with Actinomycin $D^{1,2}$
}

\author{
HEUN T. JHEE, ${ }^{3}$ SEONG S. HAN AND JAMES K. AVERY \\ The University of Michigan School of Dentistry, Ann Arbor, Michigan and \\ Yunsei University Medical School, Seoul, Korea
}

\begin{abstract}
A study has been made of the salivary glands of the rat following an injection of a sublethal dose of actinomycin D. Body weights and weights of the parotid and submandibular glands showed significant decreases during the first 7 to 14 days. The loss in weight was the greatest in the parotid gland.

Histological and cytological observations indicated that the changes in secretory cells occurred in the following order: (1) beginning of nuclear pyknosis with a rapid decrease in number and size of nuclei by 24 hours after the injection; (2) advanced stages of nuclear pyknosis with concomitant decrease in cytoplasmic basophilia and granules by day 3; (3) apparent vacuolization and rarification of cytoplasm by day 7 ; (4) beginning of nucleolar and nuclear recovery by day 10; and (5) complete cytoplasmic recovery by the end of experiment as evidenced by the return of basophilia and disappearance of vacuoles.

Paralleling the weight changes, cytological damages were greater in the parotid than in the submandibular acini. This was thought to be related to differences in nature of secretory products by the two organs. A decrease in number and pronounced irregularity in size of the granules in salivary ducts of the submandibular gland were observed but at a later time than the above mentioned changes in the acini. The significance of these changes has been discussed in light of the recently gained knowledge on the biosynthesis of nucleic acids and proteins as related to the chemical mechanism of actinomycin $D$ in the inhibition of m-RNA synthesis.
\end{abstract}

Since the isolation of actinomycin D from Streptomyces parvallus (Manaker et al., '54) its potent cytostatic effects have been widely recognized and numerous reports have already appeared describing the effects of it and related compounds on embryonic tissues (Tuchmann-Duplessis and Mercier-Parot, '58, '59 and '60; and Denis, '63), various tumors (Gregory et al., '56; Boric et al., '57 and '58; Oota et al., '57; Plummer and Walker, '58; and Awa, '61) and other normal tissues (Hackmann, '54; Friederici, '55; and Bierling, '60). Meanwhile, the chemical mechanisms of actinomycin in inducing cytostatic effects have been clarified to a large extent and experiments have proven that the drug can be used as an excellent analytic tool for studies of the biosynthesis of proteins, especially of the role played by messenger RNA (m-RNA) in this process (Kirk, '60; Reich et al., '61 and '62; Goldberg and Rabinowitz, '62; Harbers and Mueller, '62; Kahan et al., '63; Meritz, '63; Paul and Struthers, '63; Perry, '63; and Strachelin et al., '63). A survey of these articles and others illumi- nates the following: (1) m-RNA as well as soluble and ribosomal RNA is produced in the nucleus; (2) m-RNA combines with the ribosomes which are held together in the form of polyribosomes; (3) compared to other types of RNA, the turnover of m-RNA is relatively fast; and (4) the production of the m-RNA can be inhibited by actinomycin $D$ which combines specifically with DNA, resulting in the blockage of DNA-dependent RNA polymerase activity.

With respect to the digestive glands synthesizing proteineous enzymes for secretion, an insult imposed by the administration of actinomycin D would seriously affect the functioning of the gland which in turn would be reflected in its structure. In a preliminary communication we have described the weight changes and cytology of rat parotid and submandibular glands following a single injection of a sublethal

\footnotetext{
1 Based in part on a thesis for the degree of the 1 Based in part on a thesis for the degree of the
Doctor of Medical Sciences in Anatomy, Yunsei University, Seoul.

2 Supported by a grant from U.S.P.H.S. (D-1620-3) 3 Present address: Yunsei University Medical School Seoul, Korea.
} 
dose of actinomycin D (Jhee and Han, '64). The present article represents the final report of the complete study.

\section{MATERIALS AND METHODS}

Experimental design. Twenty-eight adult male Sprague-Dawley rats were used. Of these, 21 received an intraperitoneal injection of $75 \mu \mathrm{g}$ actinomycin $\mathrm{D}$ dissolved in $0.5 \mathrm{ml}$ of saline. In a previous doselethality study it was found that the dose used produced a pronounced effect on the body weight at the end of three weeks, while maintaining over $95 \%$ survival in adult male Sprague-Dawley rats weighing about $350 \mathrm{gm}$. The remaining seven rats served as controls and were injected with the same volume of saline alone. Animals were fed ad libitum with regular laboratory rat chows. Following injection, three of the experimental and one of the control rats were sacrificed on days $1,3,5$, 7, 10, 14 and 21. Each rat was weighed at the beginning of the experiment and at the time of sacrifice, and the average body weight of the experimental animals was subjected to statistical analysis.

Histological procedures. Upon sacrifice, the right parotid and submandibular gland were dissected out and weighed. Small pieces of the gland were fixed in Bouin's solution and in Zenker-formol, doubleembedded in parlodion-paraffin and sectioned at $6 \mu$.

All sections were routinely stained with hematoxylin and eosin. In addition the following staining procedures were employed for observing different aspects as indicated: Unna - Pappenheim's methyl green-pyronin for changes in nucleic acid contents; PAS-azure II for RNA content and cytoplasmic granules; aldehyde fuchsin-Masson for the general appearance of the parotid gland; and mucicarmin-hematoxylin and PAS-alcian blue for cytology of the submandibular gland.

The nucleoli to nuclei ratio. In order to obtain a quantitative estimate of the nucleolar changes of the secretory cells the ratio of the number of nucleoli to that of nuclei was studied in the following manner. Methyl green-pyronin stained sections of the parotid gland from blocs fixed in Zenker-formol were used. Under oil immersion nuclear counts were made in random areas. From each gland at least 1,500 or more nuclei of acinar cells were counted. Of these, the number of nuclei which contained nucleoli was recorded separately. The nucleoli to nuclei ratio $(\mathrm{No} / \mathrm{N})$ was obtained as follows.

No/ $\mathbf{N}=\frac{\text { No. of nuclei containing nucleoli }}{\text { Number of nuclei }} \times 100$

\section{RESULTS AND OBSERVATIONS}

\section{Weight changes}

Body weights. Figure 1 records the changes in average body weight of rats receiving an intraperitoneal injection of $75 \mu \mathrm{g}$ actinomycin D. A gradual and linear decrease was observed through the first two weeks followed by a partial recovery on day 21 . The control rats kept growing at the rate indicated.

Glandular weights. The changes in weight of the right parotid and submandibular glands are shown in figure 2. Of the two glands the parotid suffered a greater and more rapid loss of weight. By 24 hours the average glandular weight was less than $66 \%$ of the control value. As was true with body weight, the lowest point was obtained on day 14 when the glandular weight decreased to less than $50 \%$ of the control. Again, by the end of the experiment the weight showed a significant recovery. The high value obtained on day 7 is not consistent with changes in body and other organ weights.

As expected from the nature of secretory products, the weight of the submandibular gland was less affected than that of the parotid. The decrease was more gradual and did not drop as much as the latter. The low point was observed on day 10 and a moderate recovery was seen by the second week.

\section{Histological and cytological changes of the parotid}

The first sign of degeneration was the appearance of focalized areas of nuclear pyknosis in the parenchyme. Such lesion was recognized as early as 24 hours after injection and became progressively larger through the first ten days (figs. 3 and 4). Despite the progressive damage, some of the acini maintained a near normal appearance. A reversal of degenerative 


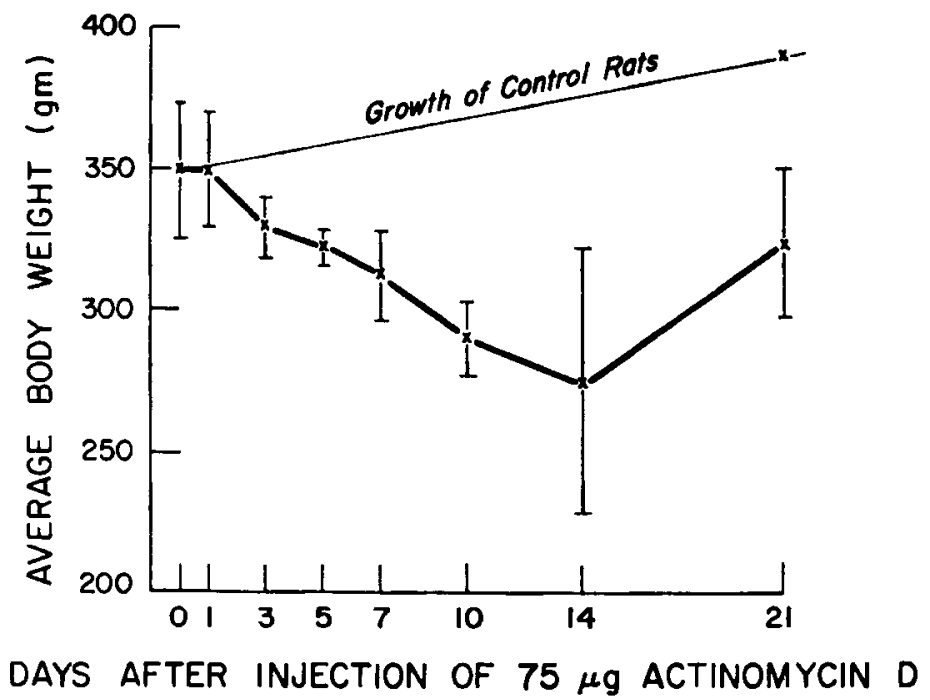

Fig. 1 The change in body weight of rats injected with actinomycin $D$ as compared with the growth of control rats.

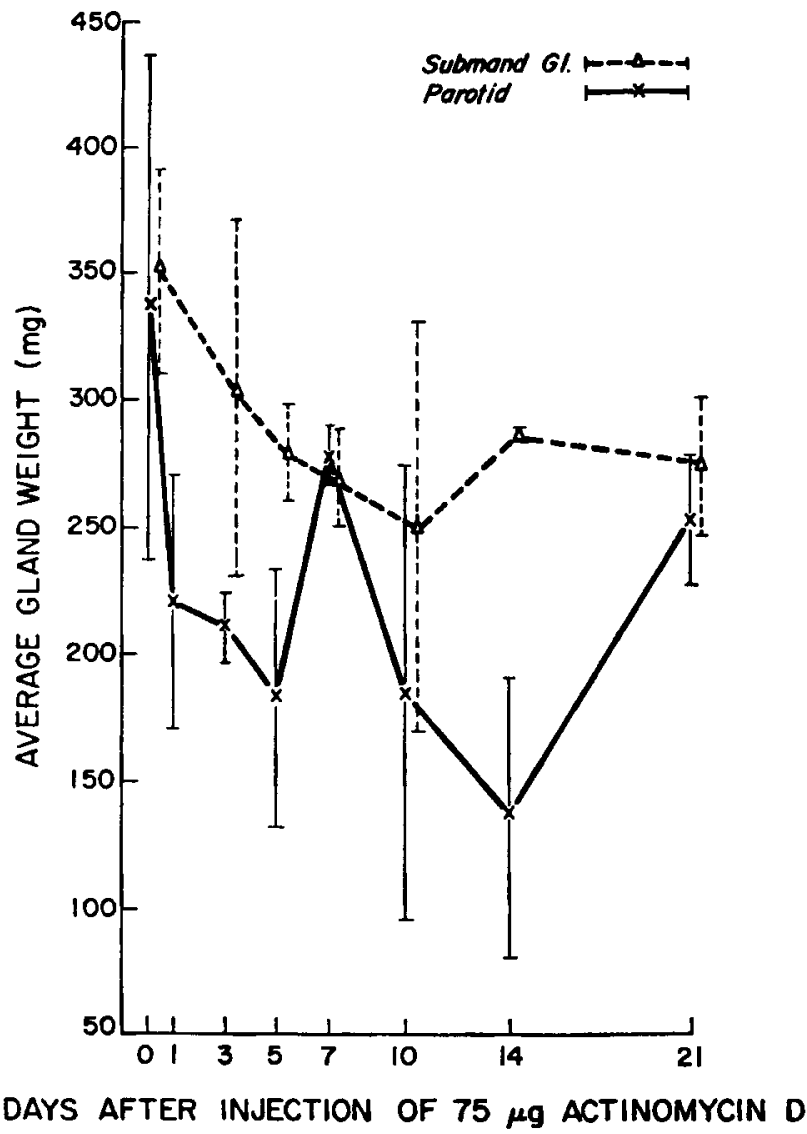

Fig. 2 The change in weight of right parotid and submandibular glands in rats injected with actinomycin D. Note the precipitous drop of the parotid weights, whereas the submandibular weights appear to parallel the changes of total body weights. 
changes was noted by day 14 and, by the end of the third week, the gland recovered an essentially normal appearance (fig. 5).

Acinar cells. Secretory cells of the parotid acini became somewhat smaller compared to those of the control (figs. 6, 7 and 8 ). The selective pyknosis of nuclei of acinar cells was apparent 24 hours following the injection and became extensive by day 3 (figs. 7 and 11 ). The nucleus of such cells was smaller than control and had an irregular, wrinkled outline. The nucleoplasm has lost the typical vesicularity and becomes increasingly condensed (figs. 11, 12 and 13). By day 7 the nucleus was so dense that only by means of differential staining could the presence or absence of the nucleoli be determined. Elsewhere the progressive rarification of the cytoplasm was notable in the affected cells (fig. 13). It seemed to result from a combination of the decrease in number of secretory granules and the gradual loss of cytoplasmic basophilia. On day 7 many cells were completely devoid of basal striations (figs. 12 and 13).

Within the rarified cytoplasm small vacuoles were present, which grew in number and size (figs. 8 and 12). They were most numerous on day 7 and were often located adjacent to the nucleus.
Sometimes their increase in size appeared to be facilitated by the coalescence of smaller vacuoles (fig. 12). In some cells the entire cytoplasm was clear and what seemed to be cytoplasmic aggregates were scattered throughout the otherwise emptylooking cytoplasm (fig. 13). Nuclei in such cells were barely recognized as a large clump adhering to the basal plasma membrane.

On day 10 changes indicating the nuclear recovery were noted in many acinar cells. The contour of nuclei became rounded and the vesicular appearance returned. Nucleoli grew larger and more prominent. By day 14 nuclei in most acinar cells were indistinguishable from those of the control (figs. 6, 9, 10 and 14). A slight recovery of the basal basophilia of acinar cells was observed on day 14 and, by day 21, many acini presented a near-normal picture. The only difference between an acinus of a control rat and that of a 21-day animal of the experimental group was the relatively small number of secretory granules observed in the latter group (fig. 14).

The appearance of ducts. All ducts of the parotid were essentially not affected. Throughout the experiment, cells of the intercalated, striated and excretory ducts appeared normal. However, a difference was noted in the content of these ducts

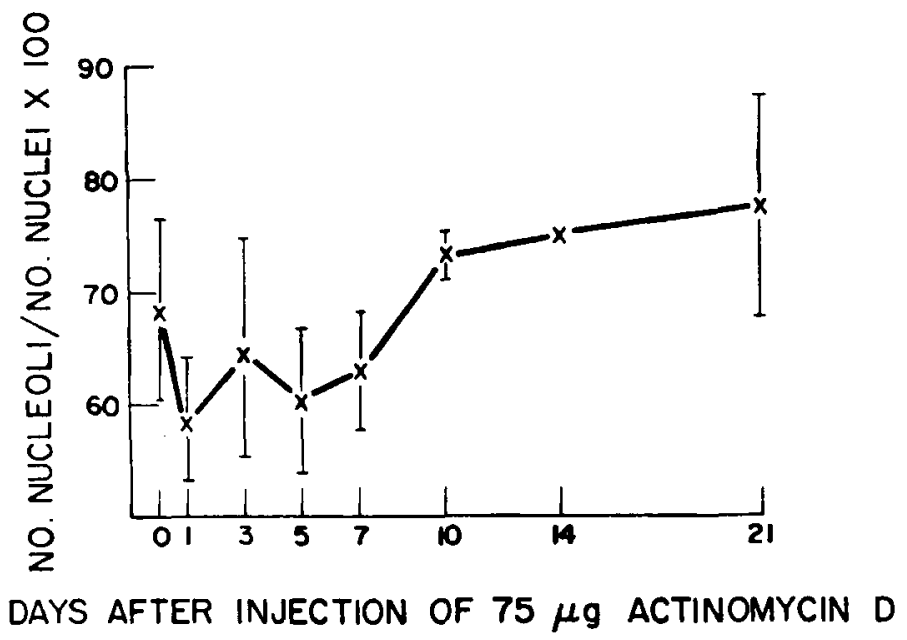

Fig. 18 The change in nucleocytoplasmic ratio of acinar cells of the parotid. A sharp drop on day 1 is followed by a gradual recovery which preceded that of body and glandular weights. 
during the early period. Twenty-four hours after the injection large masses of stainable materials were present in all portions of the duct system (figs. 15 and 16). This could be stained with eosin after Zenker-formol fixation as well as other cytoplasmic stains. The eosinophilic materials were cleared by day 3 (fig. 17). The cells of the interacinar connective tissue remained unaltered.

Changes in number of nucleoli. To ascertain the results of microscopic observation of nucleolar changes in quantitative terms, the nucleoli to nuclei ratio was studied in the manner previously described. This was considered important especially because of the fact that, during the early period of the experiment, there was a considerable variation in number of the affected cells from area to area of the same gland. Figure 18 summarizes the efforts of quantitation. Although the initial drop of the ratio during the first 24 hours was similar to weight changes of the gland, it remained basically unchanged during the first week and, by day 10, a significant increase was observed. Since the histological picture of acinar cells was progressively degenerating during this period and the glandular weight kept dropping, the early quantitative recovery of nucleoli, independent and ahead of other cytoplasmic changes, might be important. This is in agreement with the histological finding in which the nucleolar recovery was seen to proceed that of the nuclear structure and cytoplasmic basophilia.

\section{Histological changes of the submandibular gland}

Acinar cells. The basic quality of alterations produced in the submandibular gland was similar to what was observed in the parotid. The degree and extent of damage, however, was considerably less in comparison to those of the parotid. The nuclear pyknosis was moderate and the ergastoplasm appeared to persist, although a significant decrease was apparent (figs. 19 and 20). A fairly large number of vacuoles were evident by day 7 . As was true in the case of the parotid, an early nuclear recovery was followed by the return of cytoplasmic normalcy, namely the disappearance of vacuoles and a rise of basophilia.

As revealed by mucicarmin-hematoxylin staining the mucoprotein content in acinar cells was notably decreased during the initial phase and did not regain the staining intensity observable in control rats.

Ducts. Of the extensive duct system only the granulated portion of the striated duct appeared affected. Compared to changes observed in acinar cells the effect was rather slow. The ducts remained unchanged during the first 3 days when the cytoplasm was undergoing a rapid degeneration (fig. 21). On day 5 a decrease in number of the granules was observed in some specimens and by day 7 depletion of the granules was evident in many cells (fig. 22). The granules that were still present assumed irregular size and distribution. The basal striation appeared somewhat less distinct than in the controls. Occasionally wrinkling of the nuclear membrane was observed in such cells.

\section{DISCUSSION}

Glandular weights. It is significant that an early precipitous drop in weight was observed only in the parotid gland, which produces a purely proteineous secretion. The average rate of turnover of $\mathrm{m}-\mathrm{RNA}$ in parotid gland cells is not known. However, the rapidity of its turnover has been shown by various experiments using actinomycin (Levinthal et al., '62; and Staehelin et al., '63). For instance, 50 to $80 \%$ of the ribosomeassociated m-RNA breaks down within 4 to 8 hours after injection of actinomycin $D$, which specifically inhibits the nucleusdependent RNA polymerase activity. Since it has been established that the polyribosomal activities are dependent on the continued availability of the nucleus-produced m-RNA (Nirenberg and Matthaei, '61; and Rich et al., '63), the early and specific reduction of parotid weights might be taken as indicative of the arrested synthesis of digestive enzymes by the gland due to blockade of m-RNA.

The relatively slow drop in weight of the submandibular gland might be related to the nature of secretory products or the rate of enzyme synthesis by the gland. 
It is known that, although the acinar cells of the submandibular gland have a distinctly different structure from that of the ordinary mucus-secreting cells, the cells seem to secrete glycoproteins and acid mucopolysaccharides (Baker et al., '64). Thus the result of our weight studies supports the general contention that the elaboration of glycoproteins and acid mucopolysaccharides is less dependent upon $m \cdot R N A$ activities than protein biosynthesis.

The cytology of parotid cells. The sequence of cellular changes observed in this study appears to reflect faithfully the biochemical events occurring in the affected cell. Thus the early pyknosis of nuclei supports the concept that the cells indeed have suffered the initial insult to nuclei which would have stopped the production of m-RNA. The latter in turn would have prevented the formation of new polyribosomes which, at the light microscopic level, might be reflected as a decrease in basophilia as well as a secondary drop in number of secretory granules. Both of these changes have followed the nuclear pyknosis.

The interesting and dramatic changes in nucleolar morphology following actinomycin $\mathrm{D}$ administration have been recently demonstrated by Schoefl ('64) in his electron microscopic studies of cultured kidney cells. Although whether or not the same sort of changes occurs in vivo in acinar cells of the parotid gland cannot be determined with the light microscope, the rapid drop within 24 hours of the nucleoli to nuclei ratio, along with histological observations, might be taken as evidence for the specific effect of the drug on the nucleolar structure. On the basis of quantitative data on the nucleolar behavior it could be said that the direct effect on the nucleoli is, with the dose used, an immediate one which lasts for the first seven days, and that a full recovery is gained by the tenth day. It is significant that the nucleolar regeneration was evident even before the first sign of cytoplasmic recovery could be recognized, since such sequence of changes would suggest that cytoplasmic regeneration might indeed be dependent upon the nuclear recovery.
Although the nature of vacuolization and rarification of the cytoplasm cannot be visualized with clarity in light microscope observations, it has been pointed out that the ultrastructural sequence of cytoplasmic vacuolization may be similar in cells affected by different toxic agents (Lafontaine and Allard, '64). The ultrastructural aspects of the cytoplasmic vacuolization in glandular cells with impaired protein synthesis have been described by Herman and Fitzgerald, ('62), who, in a study of degenerating pancreas after ethionine administration, described the widening of endoplasmic reticulum and development of fine and coarse vacuoles containing granular disoriented membranes along with other changes such as decrease in ribosomes associated with the endoplasmic reticulum.

The accumulation of eosinophilic mass in the duct system during the initial phase of response might be related to the alteration of the flow rate, of the nature of secretory products, or of the functioning of ducts themselves. No apparent changes were observed in the structure of duct cells, although it might be possible that certain functional changes have been produced and have not been detected by the techniques employed here.

The submandibular gland. As mentioned previously, the nature of secretory products by the rat submandibular gland has been described as being composed of glycoproteins and acid mucopolysaccharides (Baker et al., '64). Baker et al. have also described that, after hypophysectomy, a procedure known to affect many protein secretory cells, the effects on cells of the submandibular gland were similar to what was observed in the parotid, although the latter was affected to a greater extent. No demonstrable changes were observed in the sublingual, a pure mucous gland. In our study also, no basic qualitative differences between structural effects on acinar cells of the parotid and those of submandibular cells were found and, therefore, reflects the involvement of both organs in protein synthesis. Thus the difference in severity of damage between the glands might be taken as an indication of the degree of their relative importance. 
Much discussion has been made on the nature and physiological significance of the granulated salivary ducts of the rodent submandibular gland (Junqueira et al., '49; Sreebny et al., '55 and '57; Baker, '58; Raynaud, '60 and '64; Tamarin et al., '63; Baker et al., '64; Juiqueira, '64; LeviMontelcini and Angeletti, '64; Screebny and Meyer, '64; and Scott and Pease, '64). A review of these permits the following summary on the matter: the granulated salivary duct might be producing a good portion of protease and a nerve growth factor; there is a sexual dimorphism which is dependent upon male sex hormones; the ultrastructure of the duct cells suggests that they are qualified for active fluid transport in large amount, as well as for the synthesis of proteins; and experimental alterations of acinar structure, such as produced by the use of isoproterenol, do not affect the duct cells, indicating the independence of the latter from acini. The slow effect of actinomycin D on the granulated segment of salivary ducts adds to the evidence that duct cells are different in their function from cells of the acinus. Only as the total glandular weight approached its bottom did the number of PAS positive granules show a measurable decrease. As to the reason why the methyl green-pyronin staining brings out the PAS positive granules as well, no explanation is sought at this time. It should be added, however, that the staining was not abolished by prior application of ribonucleases which removed cytoplasmic basophilia.

\section{LITERATURE CITED}

Awa, A. 1961 Cytological effect of chemicals on tumors. XI. Effects of thio-TEPA and actinomycin-C. on normal and neoplastic cells in vitro. Gann., 52: 49-55.

Baker, B. L. 1958 Restoration of involuted zymogenic cells in hypophysectomized rats by replacement therapy. Anat. Rec., 131: 389-404.

Baker, B. L., H. W. Clapp, Jr. and J. A. Light 1964 Hormonal influences on the cytology and physiology of salivary glands. In: Salivary Glands and Their Secretions. International Series of Monographs on Oral Biology, Ed. Sreebny and Meyer, Pergamon Press, pp. $63-81$.

Bierling, R. 1960 The effect of actinomycins on human tissue in vitro. Zschr. Krebsforsch., 63: 519-522.
Boric, F., S. Ivankovic and N. Seemayer 1957 Effect of actinomycin C. on transplantable lymphosarcoma of mice. Zschr. Krebsforsch., 62; 239-241.

Boric, F., N. Seemayer and S. Ivankovic 1957 Research on the effect of actinomycin $C$. on the Yoshida sarcoma of rats. Zschr. Krebsforsch., 62: 242-243.

Denis, H. 1963 Effects of actinomycin on neural differentiation of the ectoblast in the amphibian embryo. Exp. Cell Res., 30: 613-615.

Friederici, L. 1955 Studies on the effect of actinomycin C. (Sanamycin) on rabbit blood and hemopoietic organs and on bone marrow cultures. Zschr. Krebsforsch., 60: 553-563.

Goldberg, I. H., and M. Rabinowitz 1962 Actinomycin D. inhibition of deoxyribonucleic acid dependent synthesis of ribonucleic acid. Science, 136: 315-316.

Gregory, F. J., L. N. Pugh, T. Hata and R. Thielen 1956 The effect of actinomycin $D$. on experimental ascitic tumors in the mouse. Cancer Res., 16: 985-987.

Hackmann, C. 1954 Studies of the effect of Sanamycin (actinomycin C.) on animal organs: Spleen, thymus, lymph nodes, adrenal glands and reproductive glands. Zschr. Krebsforsch., 60: 250-255.

Habers, E., and W. Mueller 1962 On the inhibition of RNA synthesis by actinomycin. Biochem. Biophys. Res. Commun., 7: 107-110.

Herman, L., and P. J. Fitzgerald 1962 The degenerative changes in pancreatic acinar cells caused by DL-ethionine. J. Cell Biol., 12: 277-296.

Jhee, H. T., and S. S. Han 1964 Effects of actinomycin $D$. on salivary glands of the rat. Life Sciences, in press.

Junqueira, L. C. U. 1964 Studies on the physiology of rat and mouse submaxillary glands. III. On the function of the striated ducts of the mammalian salivary glands. In: Salivary Glands and Their Secretion, International Series of Monographs on Oral Biology, Ed. Sreebny and Meyer, Pergamon Press, pp. 123-128.

Junqueira, L. C. U., A. Fayer, M. Rabinovitch and L. Frankenthal 1949 Biochemical and histochemical observations on the sexual dimorphism of mice submaxillary glands. J. Cell. and Comp. Physiol., 34: 129-158.

Kahan, E., F. M. Kahan and J. Hurwitz 1963 The role of deoxyribonucleic acid in ribonucleic acid synthesis. VI. Specificity of action of actinomycin D. J. Biol. Chem., 238: 24912497.

Kirk, J. M. 1960 The mode of action of actinomycin D. Biochem. Biophys. Acta, 42: 167169.

Lafontaine, J. C., and C. Allard 1964 A light and electron microscope study of the morphological changes induced in rat liver cells by the azo dye 2-ME-DAB. J. Cell Biol., 22: 143-172.

Levi-Montalcini, R., and P. U. Angeletti 1964 Hormonal control of the NGF content in the 
submaxillary glands of mice. In: Salivary Glands and Their Secretions, International Series of Monographs on Oral Biology, Ed. Sreebny and Meyer, Pergamon Press, pp. 129-141.

Levinthal, C., A. Keynan and A. Higa 1962 Messenger RNA turnover and protein synthesis in $\mathrm{B}$. subtilis inhibited by actinomycin $\mathrm{D}$. Proc. Nat. Acad. Sci. U. S., 48: 1631-1638.

Manaker, R. A., F. J. Gregory, L C. Vining and S. A. Waksman 1954-1955 Antibiotics Ann., 853-857.

Meritz, I. 1963 Actinomycin inhibition of RNA synthesis in rat liver. Biochem. Biophys. Res. Commun., 10: 245-259.

Nirenberg, M. W., and H. Matthaei 1961 The dependence of cell-free protein synthesis in $E$. Coli upon naturally occurring or synthetic polyribonucleotides. Proc. Nat. Acad. Sci. U. S., 47: 1588-1602.

Oota, K., A. Nishibori and N. Takahashi 1957 Experimental study on the oncostatic activity of actinomycin J. I. Histological findings of therapeutic effects on Ehrilich's mouse ascites carcinoma in the ddN strain mice. J. Antibiotics, Ser. A. Tokyo, 10: 46-55.

Paul, J., and M. G. Struthers 1963 Actinomycin D.-resistant RNA synthesis in animal cells. Biochem. Biophys. Res. Commun., 11: 135-139.

Perry, R. P. 1963 Selective effects of actinomycin D. on the intracellular distribution of RNA synthesis in tissue culture cells. Exp. Cell Res., 29: 400-406.

Plummer, J., and D. G. Walker 1958 Effect of actinomycin D. on tissue cultures of normal and neoplastic cells. J. Nat. Cancer Inst., 21: 263-278.

Raynaud, J. 1960 Control hormonal de la glande sous-maxillaire de la souris. Bull. Biol. de France et de Belgique, 94: 400-523. Thése.

Reich, E., R. M. Franklin, A. J. Shatkin and E. L. Tatum 1961 Effect of actinomycin D. on cellular nucleic acid synthesis and virus production. Science, 134: 556-557.

1962 Action of actinomycin D. on animal cells and viruses. Proc. Nat. Acad. Sci. U. S., 48; 1238-1245.
Rich, A., and H. M. Goodman 1963 Mechanism of polyribosome action during protein synthesis. Nature (London), 199: 318-322.

Rich, A., and J. R. Warner 1963 A multiple ribosomal structure in protein synthesis. Proc. Nat. Acad. Sci. U.S.A., 49: 122-129.

Schoefl, G. I. 1964 The effect of actinomycin $D$. on the fine structure of the nucleolus. J. Ultrastr. Res., 10: 224-243.

Scott, B. L., and D. C. Pease 1964 Electron microscopy of induced changes in the salivary glands of the rat. In: Salivary Glands and Their Secretions, International Series of Monographs on Oral Biology, Ed. Sreebny and Meyer, Pergamon Press, pp. 13-44.

Sreebny, L. M., and J. Meyer 1964 Hormones, inanition and salivary glands. In: Salivary Glands and Their Secretions, International Series of Monographs on Oral Biology, Ed. Sreebny and Meyer, Pergamon Press, pp. 83-103.

Sreebny, L. M., J. Meyer, E. Bachem and J. P. Weinmann 1955 Postnatal changes in proteolytic activity and in the morphology of the submaxillary gland in male and female albino rats. Growth, 19: 57-74.

1957 Restoration of enzymatic activity in the submaxillary gland of the hypophysectomized albino rat. Endocrinol., 60: 200-204.

Staehelin, T., F. O. Wettstein and H. Noll 1963 Breakdown of rat-liver ergosomes in vivo after actinomycin inhibition of messenger RNA synthesis. Science, 140: 180-183.

Tamarin, A., B. Wanamaker and L. M. Sreebny 1963 The effect of inanition on the submandibular salivary glands and exocrine pancreas of the rat in mucous secretions. Ann. N. Y. Acad. Sci., 109: 609-624.

Tuchman-Duplessis, H., and L. Mercier-Parot 1958 The teratogenic activity of actinomycin D. in rats. C. R. Acad. Sci., 247: 2200-2203. 1959 Production of various malformations by administrations of actinomycin $\mathrm{D}$. to pregnant rats. C. R. Soc. Biol., 153: 386-388. 1960 Influence of actinomycin $\mathrm{D}$. on gestation and fetal development in the rabbit. C. R. Soc. Biol., 154: 914-916.

\section{PLATE}

\section{EXPLANATION OF FIGURES}

3 A survey micrograph of the right parotid gland from a control rat. Cells of acini have large and round nuclei with prominent nucleoli. Approximately $\times 336$. Fixed in Bouin's fixative and stained with hematoxylin and eosin.

4 A survey micrograph of the right parotid gland from a rat sacrificed seven days after injection. An extensive nuclear pyknosis is observed. Approximately $\times 336$. Fixed in Bouin's fixative and stained with hematoxylin and eosin.

5 A survey micrograph of the right parotid gland from a rat sacrificed 21 days after injection. Note the similarity in appearance of acinar cells to those seen in figure 3. Approximately $\times 336$. Fixed in Bouin's fixative and stained with hematoxylin and eosin. 


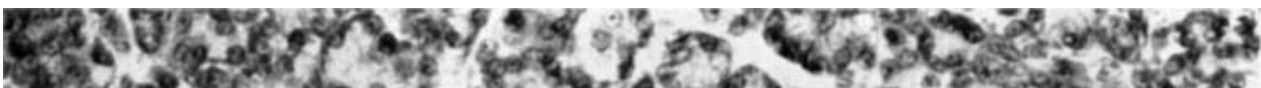

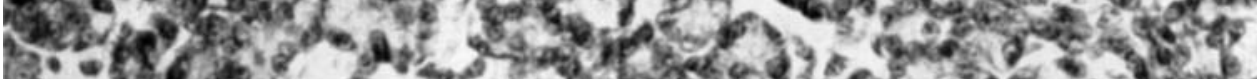

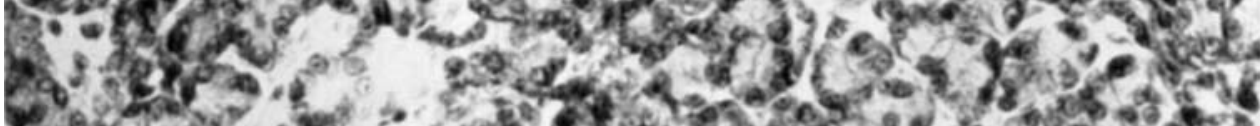
(30) of

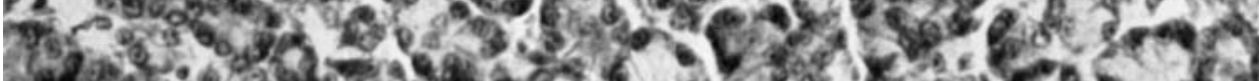

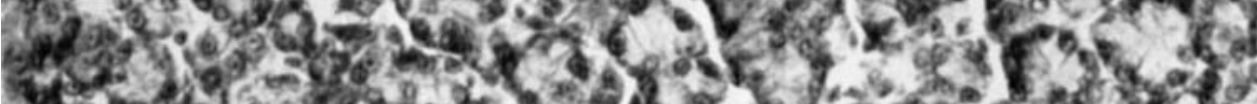

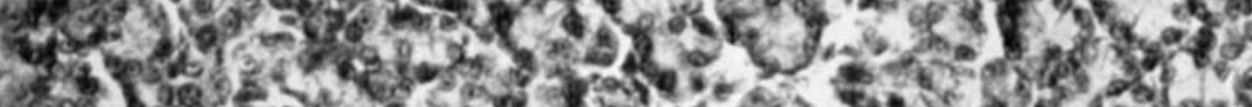

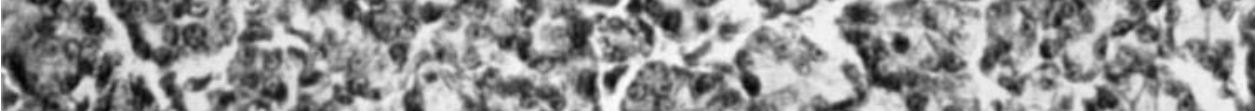

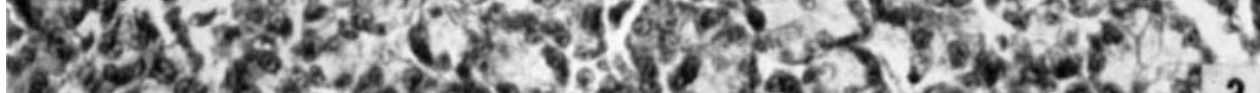

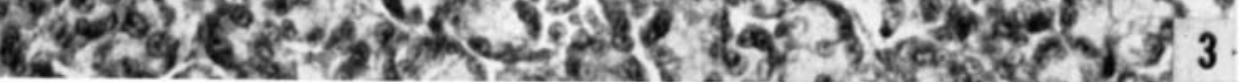
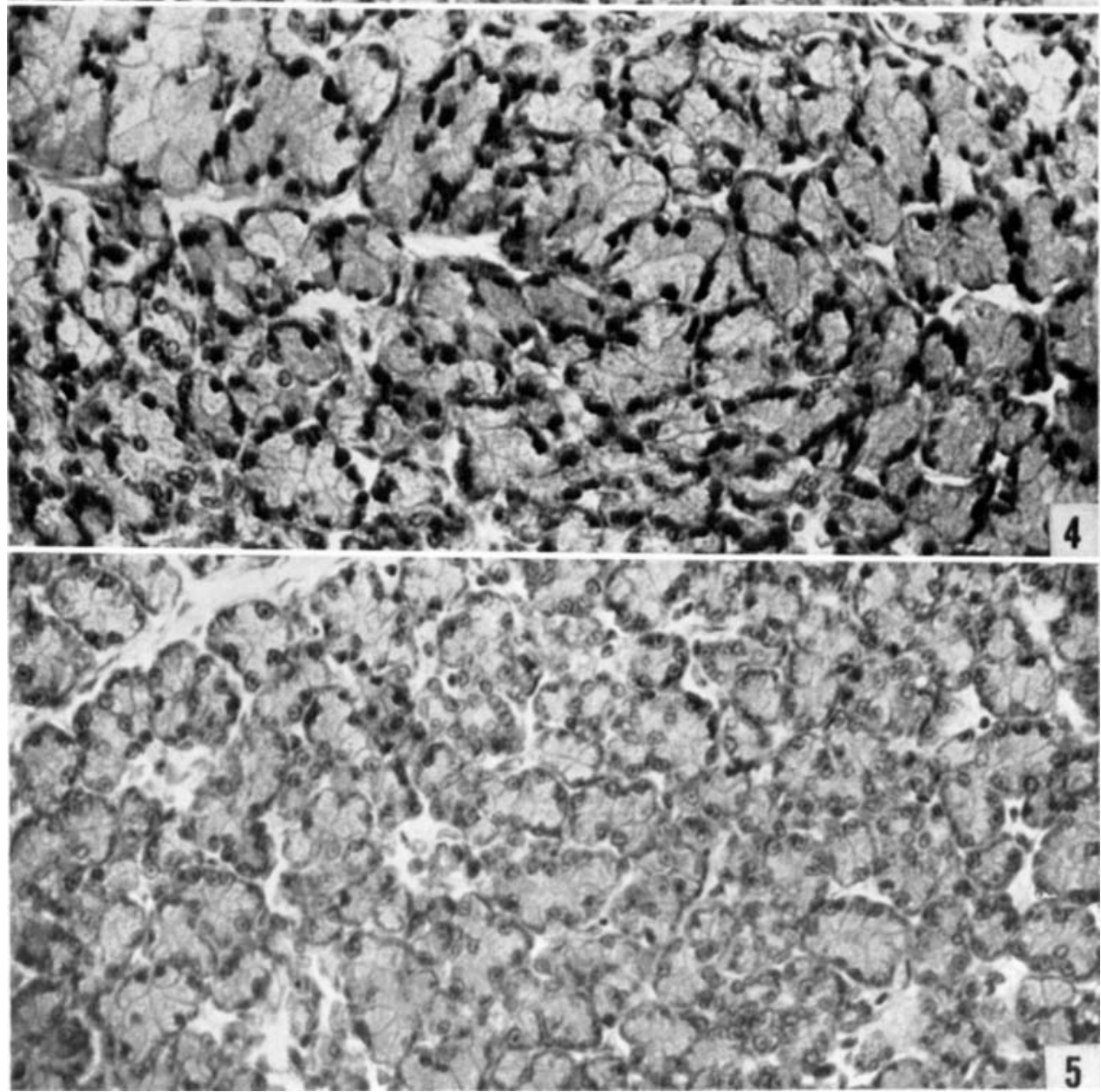
PLATE 2

EXPLANATION OF FIGURES

6 A portion of the right parotid gland from a control rat. The acini are well-defined with cells showing a clear ergastoplasm and rounded nuclei. Approximately $\times 840$. Fixed in Bouin's solution and stained with hematoxylin and eosin.

7 A portion of the right parotid gland from a rat sacrificed three days after injection. Note the selective wrinkling of nucleoplasm in acinar cells. Myoepithelial cells, and cells of the duct and interstitial connective tissue appear relatively unaffected. Approximately $\times 840$. Fixed in Bouin's solution and stained with hematoxylin and eosin. 


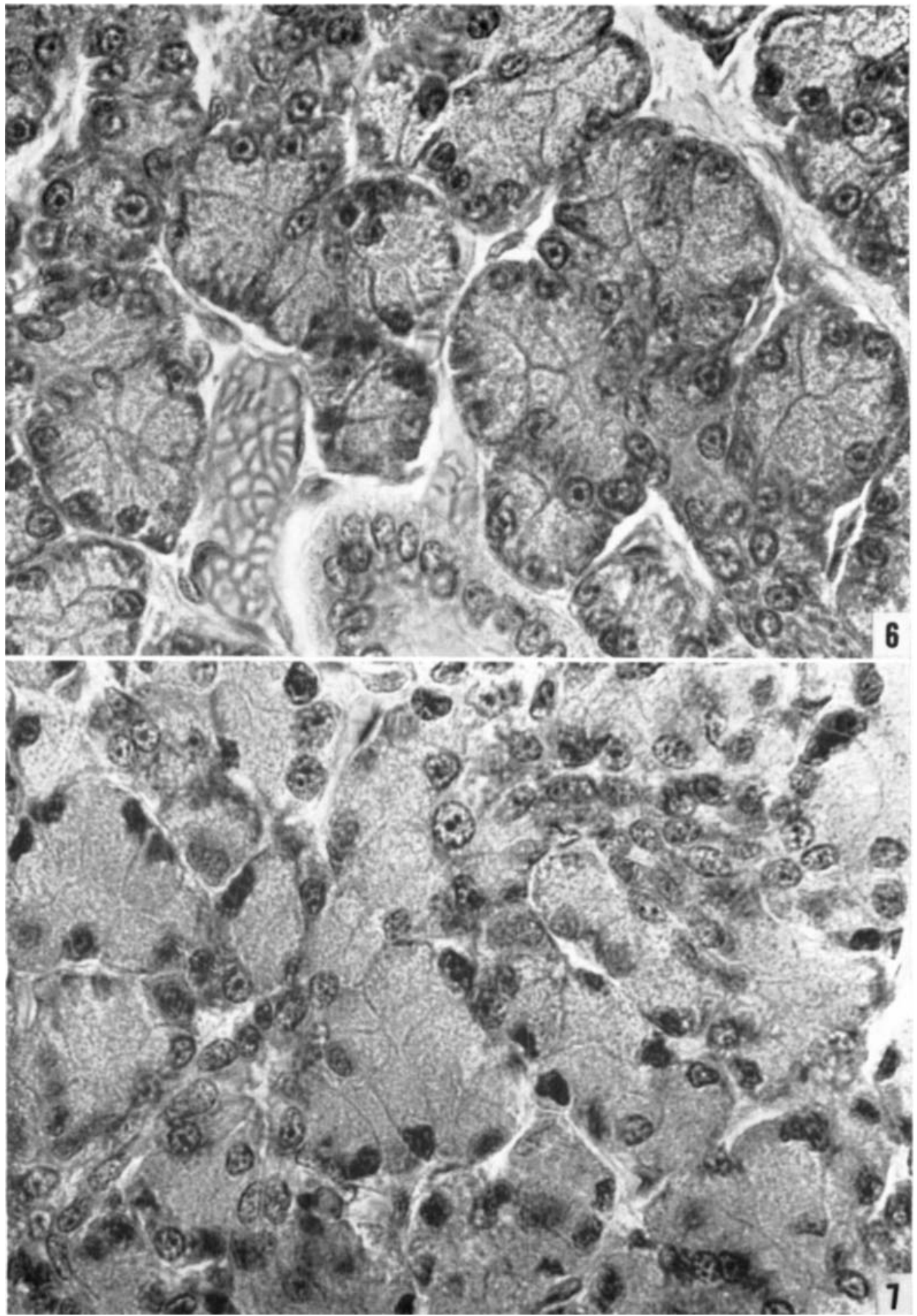


PLATE 3

\section{EXPLANATION OF FIGURES}

8 A portion of the right parotid gland from an animal sacrificed seven days after the injection. Numerous cytoplasmic vacuoles of varying sizes are seen in many acinar cells. Approximately $\times 840$. Fixed in Bouin's fixative and stained with hematoxylin and eosin.

9 A portion of the right parotid gland from a rat sacrificed 21 days after the injection. The structure of acinar cells closely resembles that of the control (see fig. 6). Approximately $\times 840$. Fixed in Bouin's solution and stained with hematoxylin and eosin. 

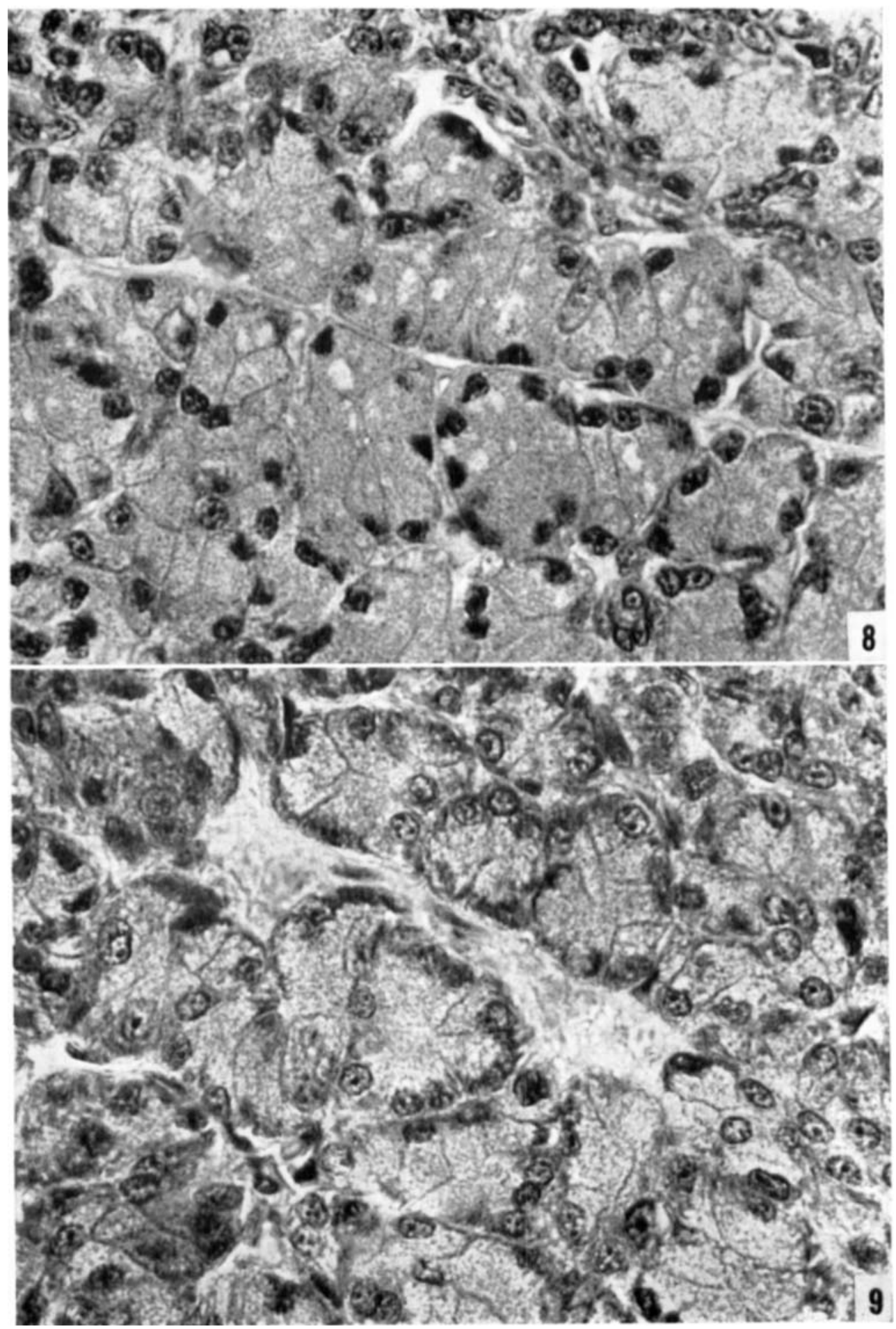
PLATE 4

EXPLANATION OF FIGURES

10 A portion of the parotid acinus from a control rat. The nucleus of secretory cells is large and vesicular. Prominent nucleoli are present. Approximately $\times 2,100$. Fixed in Zenker-formol and stained with PAS-azure II.

11 A parotid acinus from a rat sacrificed three days after the injection. The nuclear contour is irregular and the nucleoplasm hyperchromatic. Note the clumped appearance of basal basophilia and degranulation of the apical cytoplasm. Approximately $\times 2,100$. Fixed in Zenker-formol and stained with PAS-azure II.

12 An acinus of the parotid gland from a rat sacrificed seven days after the injection. The nuclear pyknosis is further advanced. The cytoplasm contains vacuoles of various sizes. Their appearance suggests that a large vacuole (V) might be formed by the coalescence of a number of smaller ones. Approximately $\times 2,100$. Fixed in Zenkerformol and stained with PAS-azure II.

13 A portion of the parotid acinus from a rat sacrificed seven days after the injection. No granules are visible and the cytoplasm appears to form filamentous aggregates creating clear regions in between the clumped masses. Approximately $\times 2,100$. Fixed in Zenker-formol and stained with PAS-azure II. 
Heun T. Jhee, Seong S. Han and James K. Avery
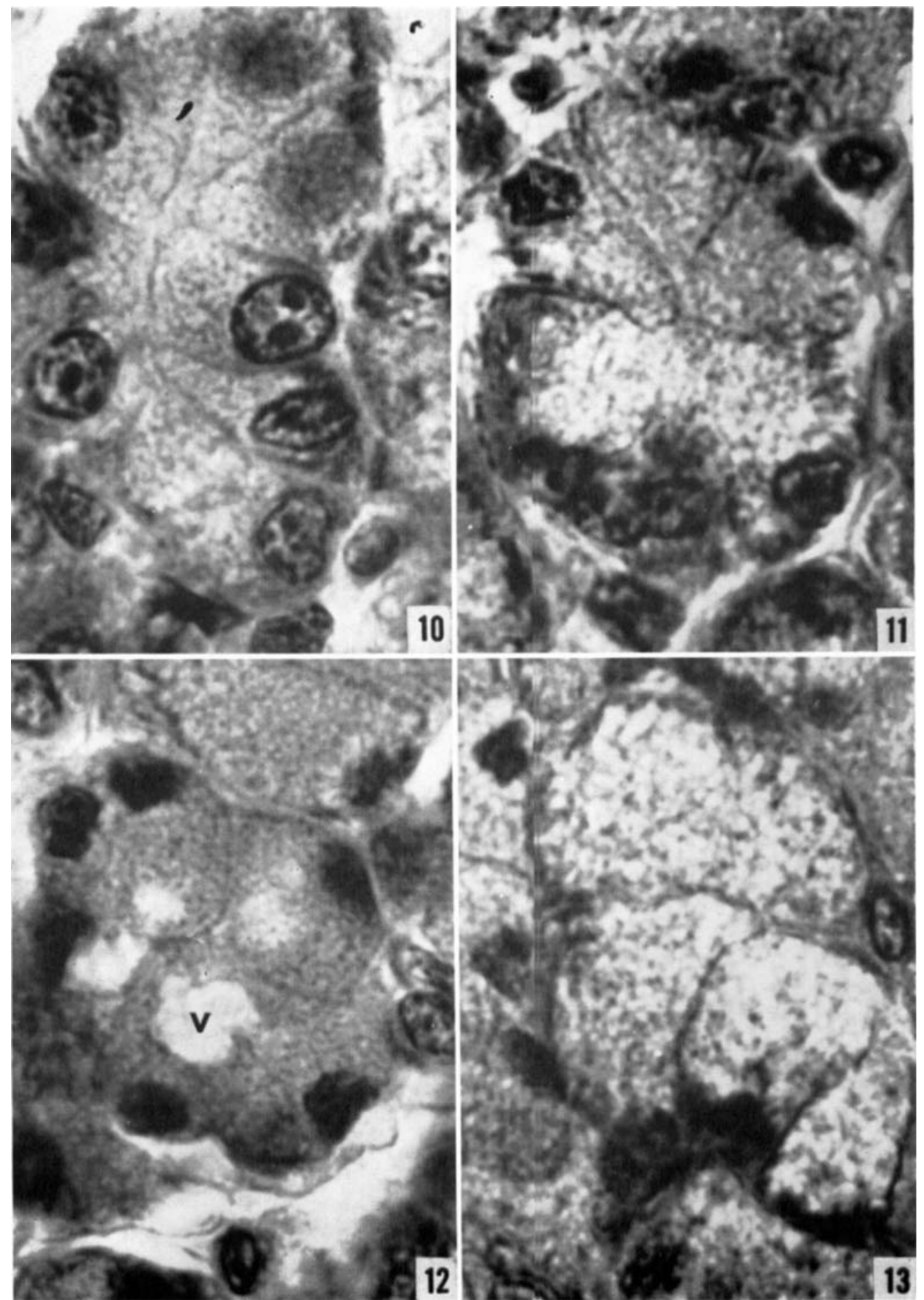
PLATE 5

EXPLANATION OF FIGURES

14 An acinus of the parotid gland from a rat sacrificed 21 days after the injection. The nucleus has become large and round again and resumed its typical vesicularity. The ergastoplasmic region is strongly basophilic. The only difference between cells of this group and those of the control is the degranulated appearance of the apical cytoplasm. Approximately $\times 2,100$. Fixed in Zenker-formol and stained with PAS-azure II.

15 A salivary duct of the parotid gland from a control rat. Approximately $\times 840$. Fixed in Zenker-formol and stained with hematoxylin and eosin.

16 Salivary ducts of the parotid gland from a rat 24 hours after the injection. Note the presence of dense materials within the lumina. Approximately $\times 840$. Fixed in Zenker-formol and stained with hematoxylin and eosin.

17 Salivary ducts of the parotid gland from a rat three days after the injection. The dense materials seen in figure 16 have disappeared and duct cells present an essentially normal appearance. Approximately $\times 840$. Fixed in Zenker-formol and stained with hematoxylin and eosin. 


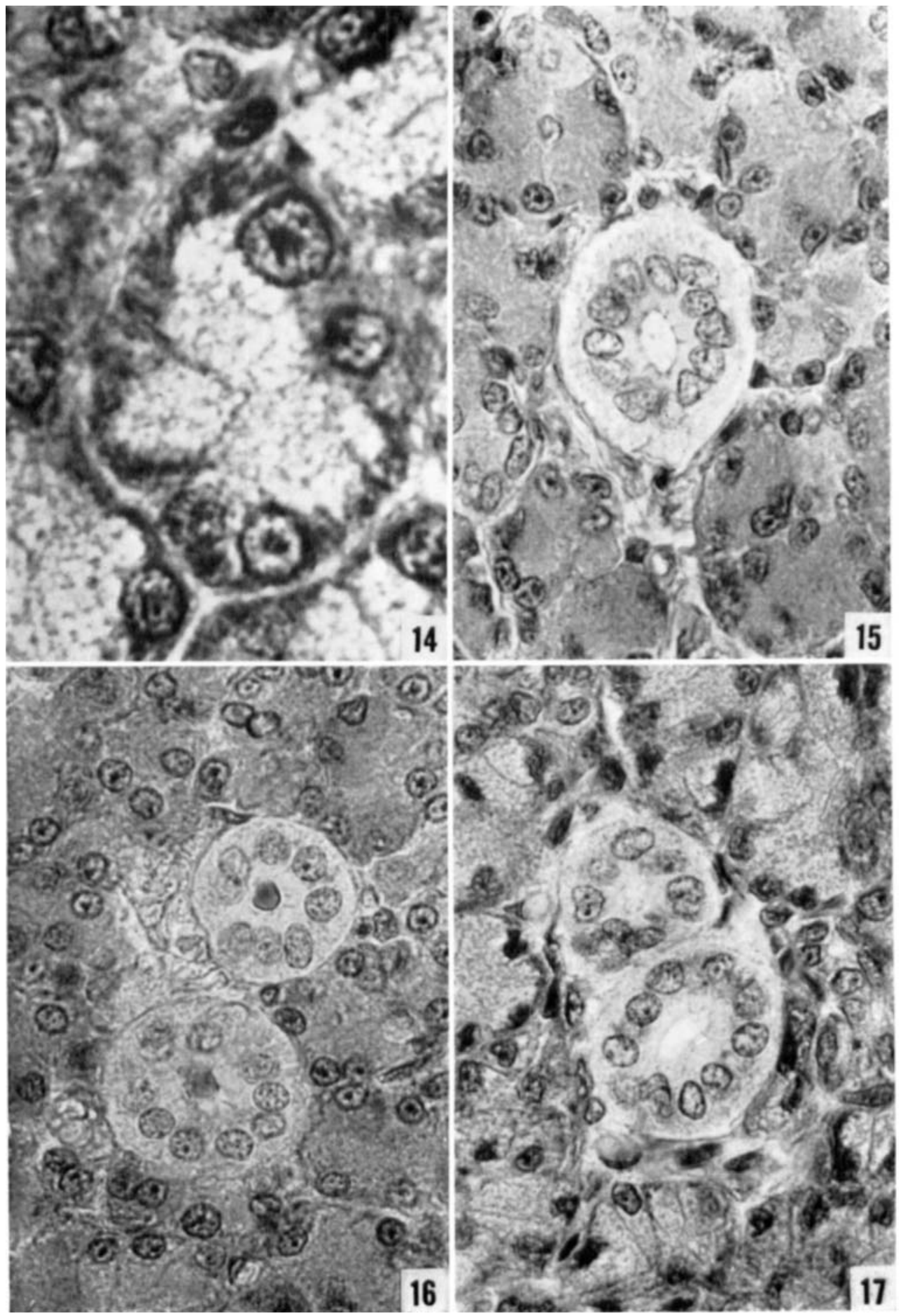


PLATE 6

EXPLANATION OF FIGURES

19 A portion of the submandibular gland from a rat seven days after the injection. Despite the extensive vacuolization of the cytoplasm the nuclear pyknosis is not as severe as in the comparable parotid section (fig. 8). Approximately $\times 840$. Fixed in Zenker-formol and stained with PAS-azure II.

20 A portion of the submandibular gland from a control rat. Approximately $\times 840$. Fixed in Bouin's fixative and stained with mucicarmin-hematoxylin. 
Heun T. Jhee, Seong S. Han and James K. Avery

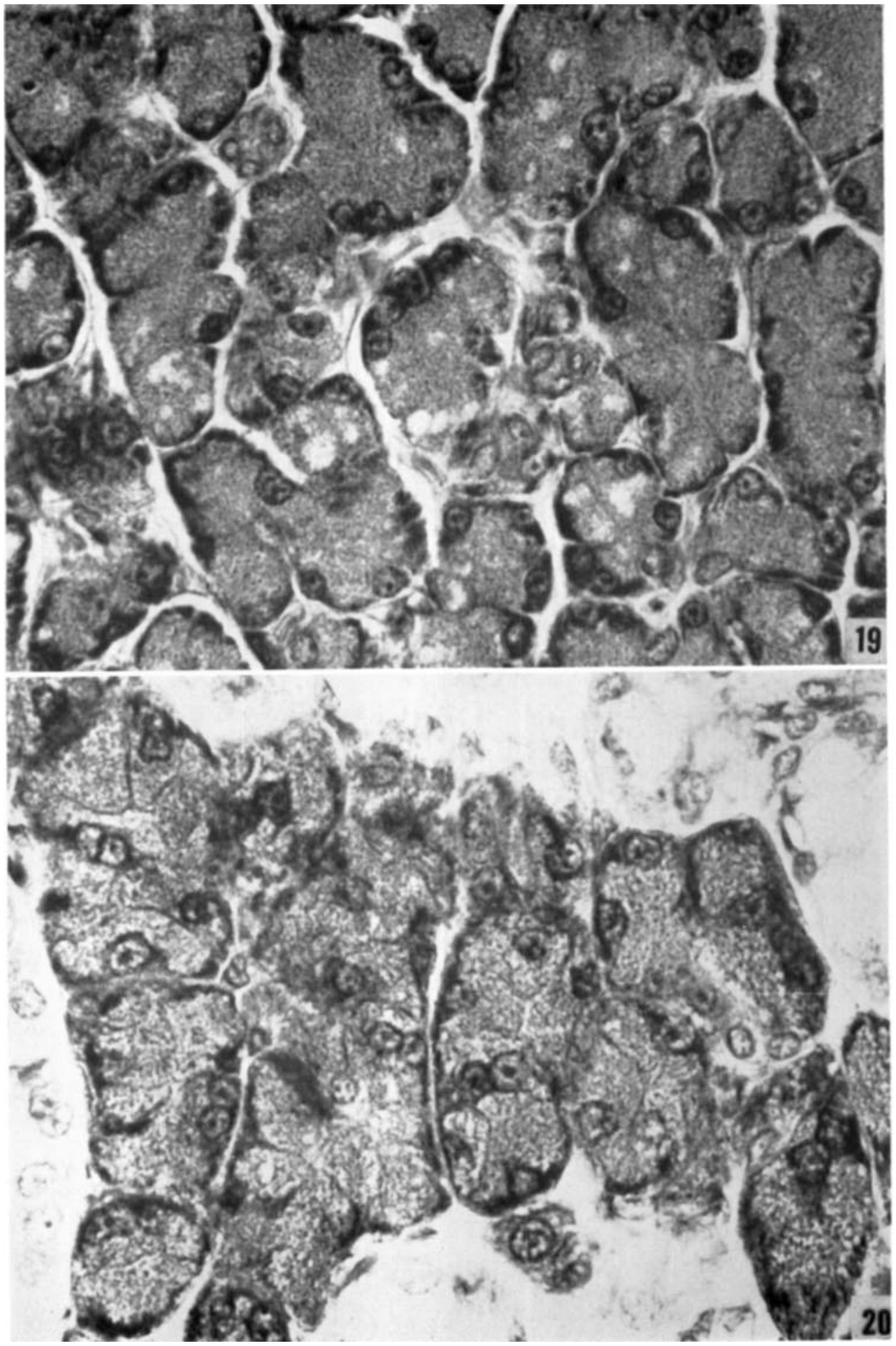




\section{PLATE 7}

EXPLANATION OF FIGURES

21 Granulated salivary ducts of the submandibular gland from a rat three days after the injection. The PAS positive granules which are stained here with methyl green-pyronin are as numerous as in the control. Approximately $\times 840$. Fixed in Zenker-formol and stained with methyl green and pyronin.

22 Granulated salivary ducts of the submandibular gland from a rat seven days after the injection. The granules are reduced in number and irregular in size. Approximately $\times 840$. Fixed in Zenker-formol and stained with methyl green and pyronin. 
Heun T. Jhee, Seong S. Han and James K. Avery
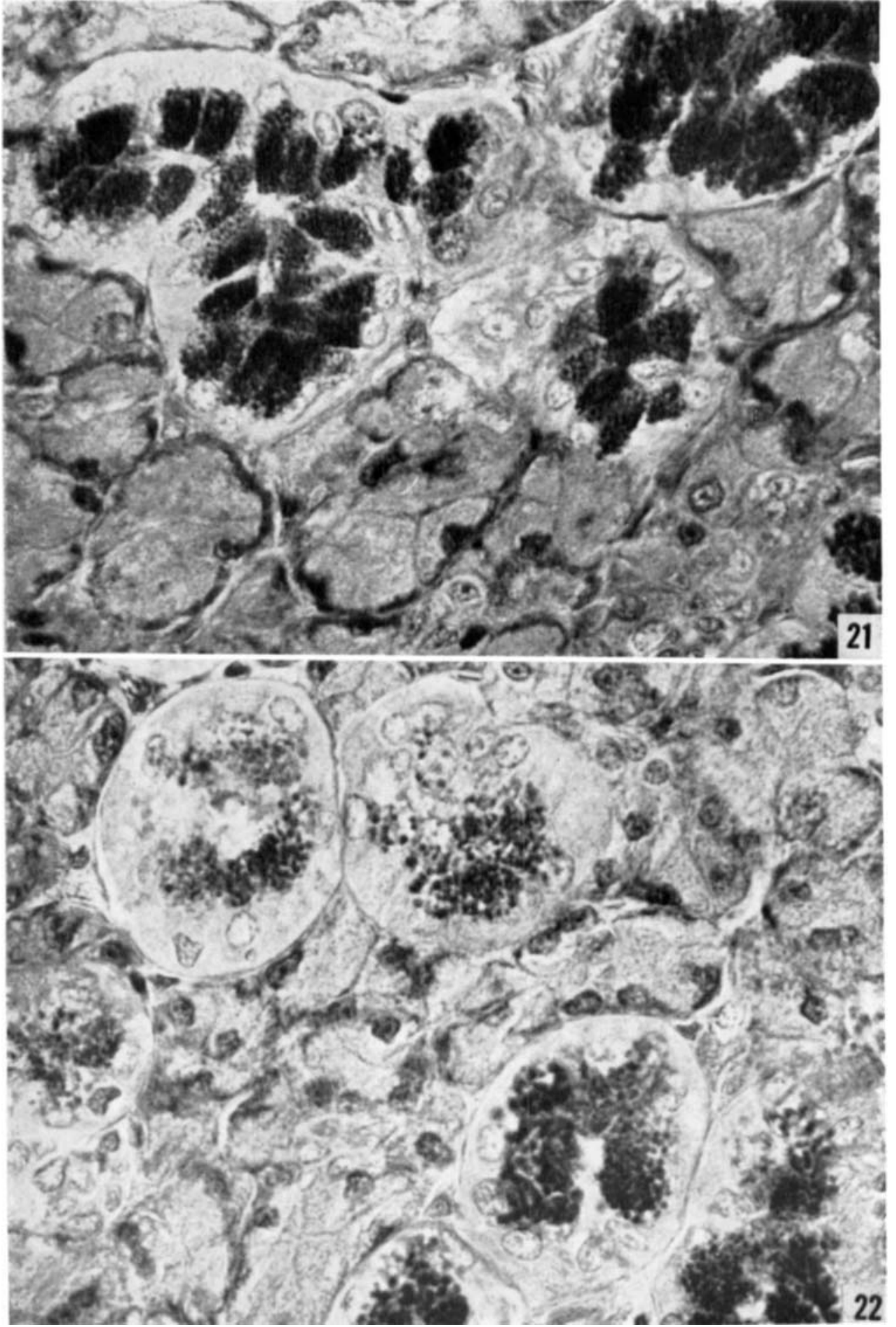